\title{
On the Mechanism of $\mathrm{Pd}(0)$-Catalyzed, $\mathrm{Cu}(\mathrm{I})$ Carboxylate-Mediated Thioorganic-Boronic Acid Desulfitative Coupling. A Non-innocent Role for Carboxylate Ligand
}

\author{
Djamaladdin G. Musaev* and Lanny S. Liebeskind ${ }^{*}$ \\ Department of Chemistry and Cherry L. Emerson Center for Scientific Computation, Emory \\ University, 1515 Dickey Drive, Atlanta, Georgia 30322.
}

\begin{abstract}
Computational studies of the mechanism of the Pd-catalyzed, $\mathrm{Cu}(\mathrm{I})$-carboxylate-mediated desulfitative coupling of thioorganics with boronic acids have determined that the requisite $\mathrm{Cu}(\mathrm{I})$ carboxylate plays multiple important roles. The $\mathrm{Cu}(\mathrm{I})$-carboxylate enhances both the transmetalation and the $\mathrm{C}-\mathrm{C}$ reductive elimination steps: it acts as a reactive transmetalation center and it provides a vital carboxylate ligand. The carboxylate ligand functions not only as an activator for the boronic acid, but it also displaces a phosphine ligand at the palladium center generating a catalytically competent mono-phosphine-palladium intermediate.
\end{abstract}

\section{Keywords}

$\mathrm{Cu}$ (I) carboxylate; density functional calculations; transmetalation; thioorganic-boronic acid coupling; non-innocent carboxylate

\begin{abstract}
Alone or in combination with other metals, copper increasingly plays a central role in many modern metal-mediated organic reactions. 1 Of the various copper co-catalysts, copper(I)carboxylate cofactors have been essential to the development of a relatively new and quite general family of efficient palladium-catalyzed desulfitative couplings of thioorganics with boronic acids that take place at neutral $\mathrm{pH}^{2}$ To date all information on the mechanistic role of the $\mathrm{Cu}(\mathrm{I})$ carboxylate in these transformations has been limited to circumstantial speculation derived from control experiments. Herein we describe the results of computational studies that have uncovered specific attributes of the $\mathrm{Cu}(\mathrm{I})$ center and an important, unanticipated mechanistic role for the carboxylate counterion.
\end{abstract}

Thioorganics do not react directly with boronic acids, neither in the presence nor absence of palladium or nickel catalysts. The addition of a stoichiometric quantity of a $\mathrm{Cu}(\mathrm{I})$ carboxylate cofactor renders the palladium-catalyzed system highly effective. ${ }^{2}$ The bottleneck of the palladium-catalyzed desulfitative coupling reaction was been assumed to be the transmetalation step because the poorly electrophilic organopalladium intermediate $\mathrm{L}_{2} \mathrm{PdR}^{1}\left(\mathrm{SR}^{2}\right.$ ) (generated upon thioorganic oxidative addition to $\mathrm{L}_{\mathrm{n}} \mathrm{Pd}(0)$, where $\mathrm{L}=\mathrm{PR}_{3}$ ) does not react with weakly nucleophilic reagents like boronic-acids. The addition of a stoichiometric quantity of a $\mathrm{Cu}(\mathrm{I})$-carboxylate, but not a $\mathrm{Cu}(\mathrm{I})$ halide, to the $\mathrm{L}_{\mathrm{n}} \mathrm{Pd}(0)$-catalyst overcomes this

dmusaev@emory.edu and chemLL1@emory.edu.

SUPPORTING INFORMATION PARAGRAPH (total 3 pages). Complete Reference for Gaussian_03, and Cartesian coordinates and total energies of all discussed structures. 
problem and facilitates the coupling of thioorganics and boronic acids at neutral $\mathrm{pH}$ (Scheme 1).

An understanding of the mechanism and the factors that govern this reaction is important in light of the increasing relevance of $\mathrm{Cu}$ in many catalytic processes. A firm understanding of mechanism will likely aid the development of a more general, truly catalytic and efficient process for thioorganic-boronic acid cross-couplings that occur at or near neutral $\mathrm{pH}$.

In order to guide experimental efforts a computational (DFT) study ${ }^{3}$ of the mechanism and factors controlling the component reactions (Scheme 1, Eqns 1-3) of the palladium-catalyzed, $\mathrm{Cu}(\mathrm{I})$-carboxylate mediated coupling of thioorganics with boronic acids has been carried out. We report herein our findings on the transmetalation (Eqn 2) and reductive elimination (Eqn 3 ) steps, only. In these studies the organopalladium intermediate $\mathrm{L}_{n} \mathrm{R}^{1} \mathrm{Pd}\left(\mu_{2}-\mathrm{SR}^{2}\right)$ was modeled using both 4- and 3-coordinated Pd-complexes, $\mathrm{L}_{2} \mathrm{MePd}\left(\mu_{2}-\mathrm{SH}\right)$ and $\mathrm{LMePd}\left(\mu_{2}-\mathrm{SH}\right.$ ) (where $\mathrm{L}=\mathrm{PH}_{3}, \mathrm{PMe}_{3}$ and $\left.\mathrm{PPh}_{3}\right)$ in order to mimic bisphosphine and monophosphine ligand environments at the Pd-center, respectively. $\mathrm{Cu}(\mathrm{HCOO})$ was used as a model for the $\mathrm{Cu}(\mathrm{I})$ carboxylate. We note that the $\mathrm{Cu}(\mathrm{I})$-mediated transmetalation may proceed via two distinct mechanisms, either through a stepwise transfer from $\mathrm{R}^{4}-\mathrm{B}(\mathrm{OH})_{2}$ to $\mathrm{Cu}(\mathrm{I})$ to produce $\mathrm{Cu}-\mathrm{R}^{4}$, which subsequently transmetalates to $\mathrm{L}_{n} \mathrm{R}^{1} \mathrm{Pd}\left(\mu_{2}-\mathrm{SR}^{2}\right)$, or by prior activation of the $\mathrm{C}-\mathrm{B}$ bond of the boronic acid in a pre-reaction complex, $\mathrm{L}_{n} \mathrm{R}^{1} \mathrm{Pd}\left(\mu_{2}-\mathrm{SR}^{2}\right) \mathrm{Cu}\left(\mathrm{R}^{3} \mathrm{COO}\right)$, formed from the $\mathrm{Cu}(\mathrm{I})$-carboxylate and $\mathrm{L}_{\mathrm{n}} \mathrm{R}^{1} \mathrm{Pd}\left(\mu_{2}-\mathrm{SR}^{2}\right)$. Since previous experimental results are not consistent with the stepwise mechanism, ${ }^{4}$ we report here a study of only the concerted mechanism of the reactions (2) and (3).

The first step of this mechanism, the addition of $\mathrm{Cu}(\mathrm{HCOO})$ to $\mathrm{L}_{n} \mathrm{MePd}\left(\mu_{2}-\mathrm{SH}\right)(\mathrm{n}=1$ and 2$)$, is a highly exothermic process and leads to the formation of the 4- and 3-coordinate pre-reaction complexes $\mathrm{L}_{2} \mathrm{MePd}\left(\mu_{2}-\mathrm{SH}\right) \mathrm{Cu}(\mathrm{HCOO}), \mathbf{I}$, and $\mathrm{LMePd}\left(\mu_{2}-\mathrm{SR}^{2}\right) \mathrm{Cu}(\mathrm{HCOO})$, Ia, which are depicted in Figure 1..$^{5}$ The resulting complexes $\mathbf{I}$ and Ia may exist in numerous isomeric forms, but we report only those isomers which are connected to the corresponding intermediates and transition states of the studied reactions, confirmed by the intrinsic reaction coordinate (IRC) method.

As seen in Figure 1, the calculated $\mathrm{Pd}-\mathrm{O}^{2}$ bond distance is significantly longer in the 4coordinated complex I than in the 3-coordinated complex Ia, suggesting that the carboxylate may facilitate displacement of a phosphine ligand from the Pd center. The calculated energy of the reaction $\mathbf{I} \rightarrow \mathbf{I a}+\mathrm{PR}_{3}, " \Delta\left(\mathrm{PR}_{3}\right)$ ", for the complexes, $\left(\mathrm{PR}_{3}\right)_{2} \mathrm{MePd}\left(\mu_{2}-\mathrm{SH}\right),\left(\mathrm{PR}_{3}\right)_{2} \mathrm{MePd}$ $\left(\mu_{2}-\mathrm{SH}\right) \mathrm{Cu}(\mathrm{HCOO})$, and $\left(\mathrm{PR}_{3}\right)_{2} \mathrm{MePd}\left(\mu_{2}-\mathrm{SH}\right) \mathrm{CuCl}$ (the latter complex is included for comparison to the carboxylate ligand) supports this conclusion: for $\mathrm{R}=\mathrm{H}, \mathrm{Me}$ and $\mathrm{Ph}$, respectively, the $\Delta\left(\mathrm{PR}_{3}\right)$ 's presented as $\Delta \mathrm{E} / \Delta \mathrm{H}$ are $10.8 /(8.9), 13.0 /(11.1)$ and $14.2(12.7) \mathrm{kcal} /$ mol for complex $\left(\mathrm{PR}_{3}\right)_{2} \mathrm{MePd}\left(\mu_{2}-\mathrm{SH}\right) ; 10.1 /(8.1), 14.3 /(12.3)$ and $16.1(14.5) \mathrm{kcal} / \mathrm{mol}$ for complex $\left(\mathrm{PR}_{3}\right)_{2} \mathrm{MePd}\left(\mu_{2}-\mathrm{SH}\right) \mathrm{CuCl}$; and 5.1/(3.2), 9.8/(8.0) and 12.1/(10.7) $\mathrm{kcal} / \mathrm{mol}$ for complex $\left(\mathrm{PR}_{3}\right)_{2} \mathrm{MePd}\left(\mu_{2}-\mathrm{SH}\right) \mathrm{Cu}(\mathrm{HCOO})$. For $\mathrm{R}=\mathrm{H}$, Me and $\mathrm{Ph}$, respectively, the inclusion of entropy effects into the calculations (those data are shown in brackets) makes the $\mathrm{PR}_{3}$ dissociation exothermic by: $\Delta \mathrm{G}=[2.6]$, [2.1] and [1.6] kcal $/ \mathrm{mol}$ for complex $\left(\mathrm{PR}_{3}\right)_{2} \mathrm{MePd}$ $\left(\mu_{2}-\mathrm{SH}\right)$; [2.7], [0.8] and [3.8] kcal/mol for complex $\left(\mathrm{PR}_{3}\right)_{2} \mathrm{MePd}\left(\mu_{2}-\mathrm{SH}\right) \mathrm{CuCl}$; and [8.5], [5.6], and $[4.4] \mathrm{kcal} / \mathrm{mol}$ for complex $\left(\mathrm{PR}_{3}\right)_{2} \mathrm{MePd}\left(\mu_{2}-\mathrm{SH}\right) \mathrm{Cu}(\mathrm{HCOO})$,. Thus, $\Delta\left(\mathrm{PR}_{3}\right)$ diminishes via the sequence $\left(\mathrm{PR}_{3}\right)_{2} \mathrm{MePd}\left(\mu_{2}-\mathrm{SH}\right) \geq\left(\mathrm{PR}_{3}\right)_{2} \mathrm{MePd}\left(\mu_{2}-\mathrm{SH}\right) \mathrm{CuCl}>\left(\mathrm{PR}_{3}\right)_{2} \mathrm{MePd}\left(\mu_{2}-\mathrm{SH}\right) \mathrm{Cu}$ (HCOO). These findings indicate that the carboxylate ligand plays an unexpected, noninnocent role in the $\mathrm{Pd}$-catalyzed, $\mathrm{Cu}$-mediated cycle. It facilitates displacement of a phosphine ligand from the Pd-center and generates a catalytically competent (less hindered and more electrophilic) monophosphine-Pd intermediate. One should note that inclusion of solvent effects into the calculations may change the above reported energetics, but it will not alter the presented trends and conclusions. Indeed, for $\mathrm{R}=\mathrm{H}$ and $\mathrm{Me}$, single point PCM calculations of 
complexes $\mathbf{I}$ and $\mathbf{I a}$ and ligand $\mathrm{PR}_{3}$ (at their gas-phase optimized geometries) reduce the calculated energy of the reaction $\mathbf{I} \rightarrow \mathbf{I a}+\mathrm{PR}_{3}$ from 5.1 and $9.8 \mathrm{kcal} / \mathrm{mol}$ to 2.2 and $7.1 \mathrm{kcal} /$ mole, respectively.

As seen from Figure 1, the boronic acid, $\mathrm{H}_{3} \mathrm{C}^{2}-\mathrm{B}(\mathrm{OH})_{2}$, may undergo transmetalation with $\mathbf{I}$ and Ia via both " $P d$-side" and " $C u$-side" pathways. In the $P d$-side pathway, the $\mathrm{Pd}$ and $\mathrm{O}^{2}$ centers [from the $\mathrm{O}^{2}=\mathrm{C}(\mathrm{H}) \mathrm{O}^{1}$ - ligand] act cooperatively to cleave the $\mathrm{B}-\mathrm{C}^{2}$ bond of boronic acid, while in the $\mathrm{Cu}$-side pathway the $\mathrm{Cu}$ and $\mathrm{O}^{1}$ centers [from the $\mathrm{O}^{2}=\mathrm{C}(\mathrm{H}) \mathrm{O}^{1}$ - ligand] perform the same function. The transition states (TS1_Pd, TS1a_Pd, TS1_Cu, and TS1a_Cu) corresponding to these $\mathrm{H}_{3} \mathrm{C}^{2}-\mathrm{B}(\mathrm{OH})_{2}$ activation are also presented in Figure 1 .

The nature of these transition states was confirmed by performing vibrational normal mode analysis and intrinsic reaction coordinate (IRC) calculations. ${ }^{6}$ As seen from Scheme 2 and Scheme 3, the calculated barriers (based on their enthalpy $\Delta \mathrm{H}$ values,3) associated with the $P d$-side and $\mathrm{Cu}$-side transmetalations are (33.0) and (21.7) kcal/mol for the 4-coordinate complex I (R=H), and (19.4) and (22.2) $\mathrm{kcal} / \mathrm{mol}$ for the 3-coordinate complex Ia $(\mathrm{R}=\mathrm{H})$, respectively. These values are slightly higher for the complexes with $\mathrm{R}=\mathrm{Me}$ and $\mathrm{Ph}$ (second and third lines in these Figures), especially for $P d$-side transition states. In other words, for the 4-coordinated Pd-complex I (modeling a bisphosphine ligand environment), the $\mathrm{Cu}$-side transmetalation is more favorable than the $P d$-side transmetalation (Scheme 2). For the 3coordinated Pd-complex Ia, the $P d$-side and $\mathrm{Cu}$-side transmetalations by boronic acid occur with similar energy barriers (Scheme 3). Perhaps not surprisingly, an increase in size of the phosphine ligands favors a $\mathrm{Cu}$-side over a $P d$-side transmetalation. This trend is also partially affected by an increase in the $\mathrm{Pd}-\mathrm{PR}_{3}$ bonding energy via $\mathrm{PR}_{3}=\mathrm{PH}_{3}<\mathrm{PMe}_{3}<\mathrm{PPh}_{3}$ (see discussion, above), which is due to a change in the electronic nature of phosphine ligands.

Comparison of the calculated barrier heights for the B-C ${ }^{2}$ bond activation by 4-coordinate complex I and 3-coordinate complex Ia (Scheme 2 and Scheme 3, respectively) shows that dissociation of one of the $\mathrm{PR}_{3}$ groups from I clearly enhances the $P d$-side transmetalation step. As demonstrated above, the presence of a hemilabile carboxylate ligand ${ }^{7}$ assists the displacement a phosphine ligand from the Pd-center and facilitates the generation of Ia. Furthermore, analysis of the geometries of the transition state structures TS1_Pd, TS1a_Pd, TS1_Cu, and TS1a_Cu show that one of the O-atoms of the carboxylate ligand is directly involved in the B-C bond activation simultaneously with the corresponding transition metal centers $(\mathrm{Pd}$ or $\mathrm{Cu})$. Previously, a similar result was reported by Sakaki and co-workers for mononuclear complexes $\mathrm{M}\left(\eta^{2}-\mathrm{O}_{2} \mathrm{CH}\right)$ of $\mathrm{Pd}$ and $\mathrm{Pt}$, where the formate ligand assists benzene and methane $\mathrm{C}-\mathrm{H}$ bond activation. ${ }^{8}$

As seen in Scheme 2 and Scheme 3 the reductive elimination, which occurs at the Pd-center regardless of the site of transmetalation, is the rate-determining step for both the $P d$-side and $\mathrm{Cu}$-side transmetalation pathways of the reaction involving $\mathbf{I}$, and for the $P d$-side transmetalation pathway of the reaction involving Ia. For the reaction involving the 4coordinated reactant $\mathbf{I}$ (Scheme 2), the reductive elimination occurs directly from the $P d$ side transmetalation product, while in the $\mathrm{Cu}$-side pathway, reductive elimination also occurs at $\mathrm{Pd}$, but prior to reductive elimination, the transmetalation product, $\left(\mathrm{PR}_{3}\right)_{2}\left(\mathrm{CH}_{3}\right) \mathrm{Pd}\left(\mu_{2}-\mathrm{SH}\right)$ $\mathrm{CuMe}$, must dissociate one of $\mathrm{PR}_{3}$-groups from $\mathrm{Pd}$ and generate the bridging Me intermediate $\left(\mathrm{PR}_{3}\right)\left(\mathrm{CH}_{3}\right) \mathrm{Pd}\left(\mu_{2}-\mathrm{SH}\right)\left(\mu_{2}-\mathrm{Me}\right) \mathrm{Cu}$. In contrast, in the case of the reaction involving the 3coordinated reactant Ia (Scheme 3), reductive elimination occurs directly from the transmetalation products for both the $\mathrm{Pd}$-side and $\mathrm{Cu}$-side pathways. In general, the reductive elimination from the 3-coordinated Pd-complex Ia is favorable, especially for the $\mathrm{Cu}$-side pathway, which occurs only (20.3) and (23.3) $\mathrm{kcal} / \mathrm{mol}$ overall barrier for $\mathrm{R}=\mathrm{H}$ and $\mathrm{Me}$, respectively. 
In summary, the current results show that the requisite $\mathrm{Cu}(\mathrm{I})$ carboxylate cofactor present in $\mathrm{Pd}$-catalyzed, $\mathrm{Cu}$-mediated desulfitative couplings plays multiple roles. The $\mathrm{Cu}$-center of the complexes I and Ia: (i) functions as a lynch-pin that both coordinates to thiolate sulfur and provides a carboxylate ligand that facilitates phosphine dissociation from the palladium center; (ii) enhances thermodynamicity for the transmetalation step by forming a strong ( $c a 45-55$ $\mathrm{kcal} / \mathrm{mol}^{5}$ ) $\mathrm{Cu}-\mathrm{S}$ bond; (iii) acts as a reactive transmetalation center for the boronic acid (the calculated B-C activation barriers are significantly smaller for $\mathrm{Cu}$-side pathway than $P d$-side one), especially for 4-coordinated complex I; and (iv) facilitates reductive elimination by forming a strong bond with the thiolate sulfur. The carboxylate ligand enhances the transmetalation step by facilitating the displacement of a phosphine ligand from the Pd-center thus generating a catalytically competent monophosphine-Pd intermediate, as well as by acting as a reactive transmetalation center for the boronic acid.

\section{Supplementary Material}

Refer to Web version on PubMed Central for supplementary material.

\section{Acknowledgments}

The present research is in part supported by the grant (DE-FG02-03ER15461 from U.S. Department of Energy and through grant No. GM066153 from the National Institutes of General Medical Sciences, DHHS. The use of computational resources at the Cherry Emerson Center for Scientific Computation is acknowledged.

\section{References}

1. (a) Phipps RJ, Gaunt MJ. Science (Washington, D.C.) 2009;323:1593-1597. (b) Buchwald SL, Bolm C. Angew. Chem., Int. Ed. Engl. 2009 Early View. (c) Lipschutz BH, Yamamoto Y. Chem. Rev 2008;108:2793-2795. [PubMed: 18698732] (d) Evano G, Blanchard N, Toumi M. Chem. Rev 2008;108:3054-3131. [PubMed: 18698737] (e) Harutyunyan SR, Hartog T. d. Geurts K, Minnaard AJ, Feringa BL. Chem. Rev 2008;108:2824-2852. [PubMed: 18698733] (f) Alexakis A, Bäckvall JE, Krause N, Pàmies O, Diéuez M. Chem. Rev 2008;108:2796-2823. [PubMed: 18671436] (g) Beletskaya IP, Cheprakov AV. Coord. Chem. Rev 2004;248:2337-2364. (h) Stuart DR, Fagnou K. Science (Washington, D.C.) 2007;316:1172-1175. (i) Do H-Q, Daugulis O. J. Am. Chem. Soc 2007;129:12404-12405. [PubMed: 17887762] (j) Ley SV, Thomas AW. Angew. Chem., Int. Ed. Engl 2003;42:5400-5449. [PubMed: 14618572] (k) Wipf P. Synthesis 1993:537-557.

2. The desulfitative coupling of thioorganics with boronic acids using palladium catalysts and stoichiometric $\mathrm{Cu}(\mathrm{I})$ carboxylate cofactors represents a "first-generation" system. The chemistry takes place at neutral $\mathrm{pH}$ and at or near ambient temperature and provides improved functional group compatibility relative to organolithium, -magnesium, and -zinc reagents. For a recent review see: Prokopcov H, Kappe CO. Angew. Chem., Int. Ed 2009;48:2276-2286. as well as 2 more recent papers: Li H, Yang H, Liebeskind LS. Org. Lett 2008;10:4375-4378. [PubMed: 18759432] and Han J, Gonzalez O, Aguilar-Aguilar A, Peña-Cabrera E, Burgess K. Org. Biomol. Chem 2009;7:34-36. [PubMed: 19081940] Second generation systems have been developed that are palladium-free and use only catalytic quantities of Cu: Villalobos JM, Srogl J, Liebeskind LS. J. Am. Chem. Soc 2007;129:15734-15735. [PubMed: 18047333] and Liebeskind LS, Yang H, Li H. Angew. Chem., Int. Ed 2009;48:1417-1421.

3. Computational Methods. The geometry and vibrational frequencies of the reported structures were calculated at the B3LYP level [(a) Becke AD. Phys Rev A 1988;38:3098-3100. [PubMed: 9900728], and J. Chem. Phys 1993;98:5648-5654. (b) Lee C, Yang W, Parr RG. Phys Rev B 1988;37:785-789.] of theory using the LANL2DZ basis sets and associated ECP for Pd and Cu [Hay PJ, Wadt WR. J. Chem. Phys 1985;82:299-310.]. For the other atoms, 6-31G(d) basis sets were used. The dielectric effects from the surrounding environment were estimated using the self-consistent reaction field IEFPCM method [Cances E, Mennucci B, Tomasi J. J. Chem. Phys 1997;107:3032-3041.]. THF was used as a solvent. All calculations were performed by the Gaussian_03 program [see: Frisch, MJ., et al. Rev. B.01. Gaussian, Inc.; Pittsburgh PA: 2003. Gaussian 03]. Throughout this paper we discuss the calculated enthalpy $(\Delta \mathrm{H})$ values. Since the entropy effect for gas-phase reaction could be significantly 
larger than that in the solution, where the real reaction takes place, here we do not discuss the entropy corrections, while the calculated gas-phase $\Delta \mathrm{G}$ values are given in Schemes 2 and 3. Inclusion of solvent effects (italic numbers in Schemes 2 and 3) leads qualitatively to the same conclusions, and therefore will not be discussed either.

4. Liebeskind LS, Srogl J. J. Am. Chem. Soc 2000;122:11260-11261.

5. Calculated exothermicity $(\Delta \mathrm{E} /(\Delta \mathrm{H}) /(\Delta \mathrm{G}))$ of the reaction $\left(\mathrm{PR}_{3}\right)_{2} \mathrm{MePd}(\mu 2-\mathrm{SH})+\mathrm{Cu}(\mathrm{HCOO}) \rightarrow$ $\left(\mathrm{PR}_{3}\right)_{2} \mathrm{MePd}\left(\mu_{2}-\mathrm{SH}\right) \mathrm{Cu}(\mathrm{HCOO})$ are: 49.2/(47.3)/[33.8], 53.6/(51.7)/[38.4] and 56.2/(54.7)/[41.1] $\mathrm{kcal} / \mathrm{mol}$ for $\mathrm{R}=\mathrm{H}$, Me and $\mathrm{Ph}$, respectively.

6. Gonzalez C, Schlegel HB. J. Chem. Phys 1990;94:5523-5527.

7. (a) Slone, CS.; Weinberger, DA.; Mirkin, CA. Progress in Inorganic Chemistry. Karlin, KD., editor. Wiley \& Sons Inc.; New York: 1999. p. 233 (b) Rogers CW, Y. Zhang Y, Patrick BO, Jones WE Jr. Wolf MO. Inorg. Chem 2002;41:1162-1169. [PubMed: 11874351]

8. Bismas B, Sugimoto M, Sakaki S. Organometallics 2000;19:3895-3908. 


$$
\begin{aligned}
& \mathrm{R}^{1}-\mathrm{SR}^{2}+\mathrm{L}_{n} \mathrm{Pd}(0) \underset{\text { add'n }}{\stackrel{\text { oxid. }}{\longrightarrow}} \mathrm{L}_{n} \mathrm{Pd}\left(\mathrm{R}^{1}\right)\left(\mathrm{SR}^{2}\right) \stackrel{\mathrm{CuOCOR}^{3}}{\longrightarrow} \mathrm{L}_{n} \mathrm{Pd}\left(\mathrm{R}^{1}\right)\left(\mu_{2}-\mathrm{SR}^{2}\right)\left(\mathrm{Cu}-\eta^{1}-\mathrm{OCOR}^{3}\right) \\
& L_{n} P d\left(R^{1}\right)\left(\mu_{2}-S R^{2}\right)\left(C u-\eta^{1}-\mathrm{OCOR}^{3}\right) \underset{\text { transmetalation }}{\mathrm{R}^{4} \mathrm{~B}(\mathrm{OH})_{2}}\left\{\left[\mathrm{~L}_{n} \mathrm{Pd}\left(\mathrm{R}^{1}\right)\left(\mathrm{R}^{4}\right)+\left(\mathrm{R}^{2} \mathrm{~S}\right)(\mathrm{Cu})\left[\eta^{1}-\mathrm{R}^{3} \mathrm{COO}-\mathrm{B}(\mathrm{OH})_{2}\right]\right\}\right.
\end{aligned}
$$

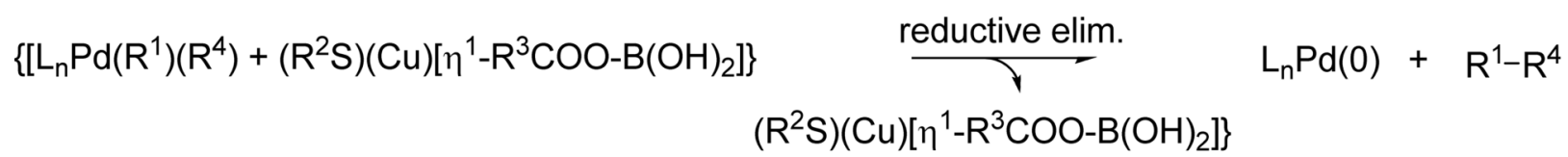

Scheme 1.

The Component Reactions of the $\mathrm{Pd}(0)$-catalyzed, $\mathrm{Cu}(\mathrm{I})$-Carboxylate Mediated Desulfitative Coupling of Thioorganics with Boronic acids. 

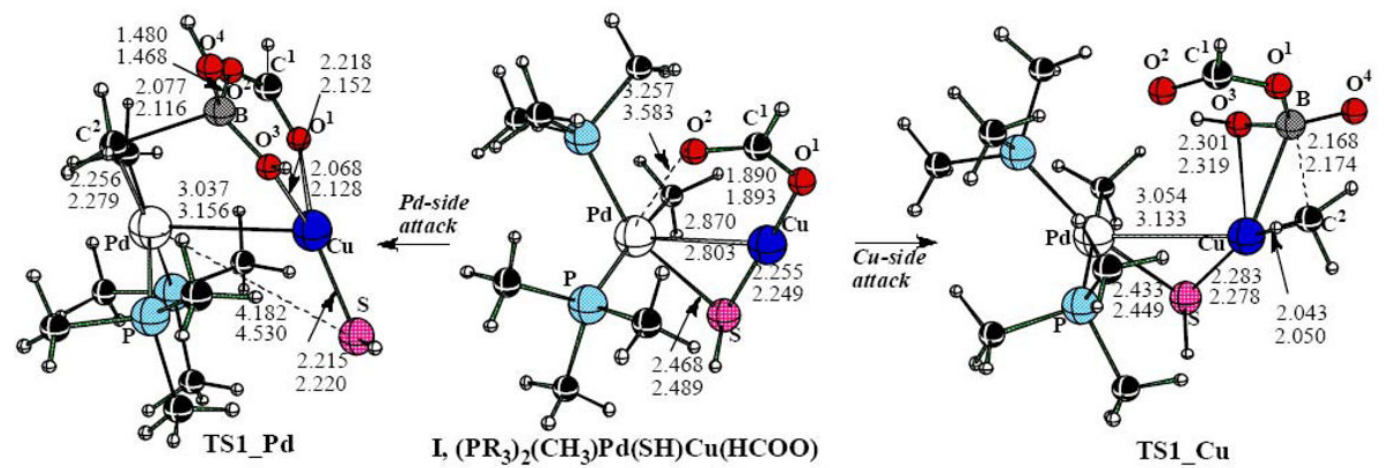

$\mathrm{I},\left(\mathrm{PR}_{3}\right)_{2}\left(\mathrm{CH}_{3}\right) \mathrm{Pd}(\mathrm{SH}) \mathrm{Cu}(\mathrm{HCOO})$

TS1_Cu
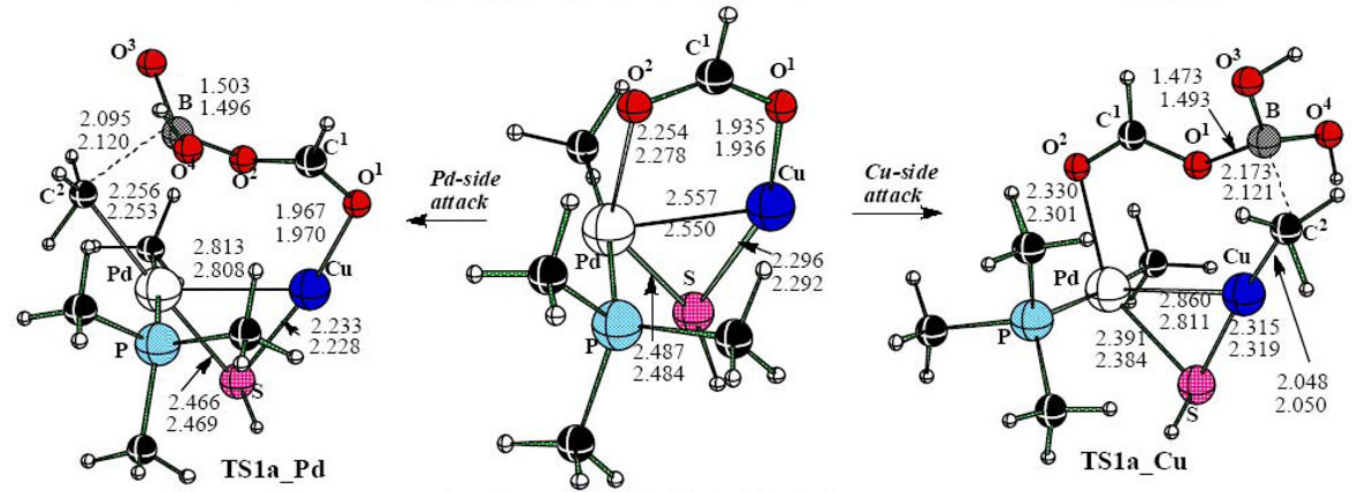

Ia, $\left(\mathrm{PR}_{3}\right)\left(\mathrm{CH}_{3}\right) \mathrm{Pd}(\mathrm{SH}) \mathrm{Cu}(\mathrm{HCOO})$

Figure 1.

Calculated Important Bond Distances ${ }^{\mathrm{a}}$ of the Complexes I and Ia, and Transmetalation Transition States TS1_Pd, TS1a_Pd, TS1_Cu and TS1a_Cu.

a Bond Distances in $\AA$ The numbers in the first and second lines are for $\mathrm{R}=\mathrm{H}$ and $\mathrm{Me}$, respectively. To minimize clutter is this Figure, values for $\mathrm{R}=\mathrm{Ph}$ are provided in the Supporting Information. 


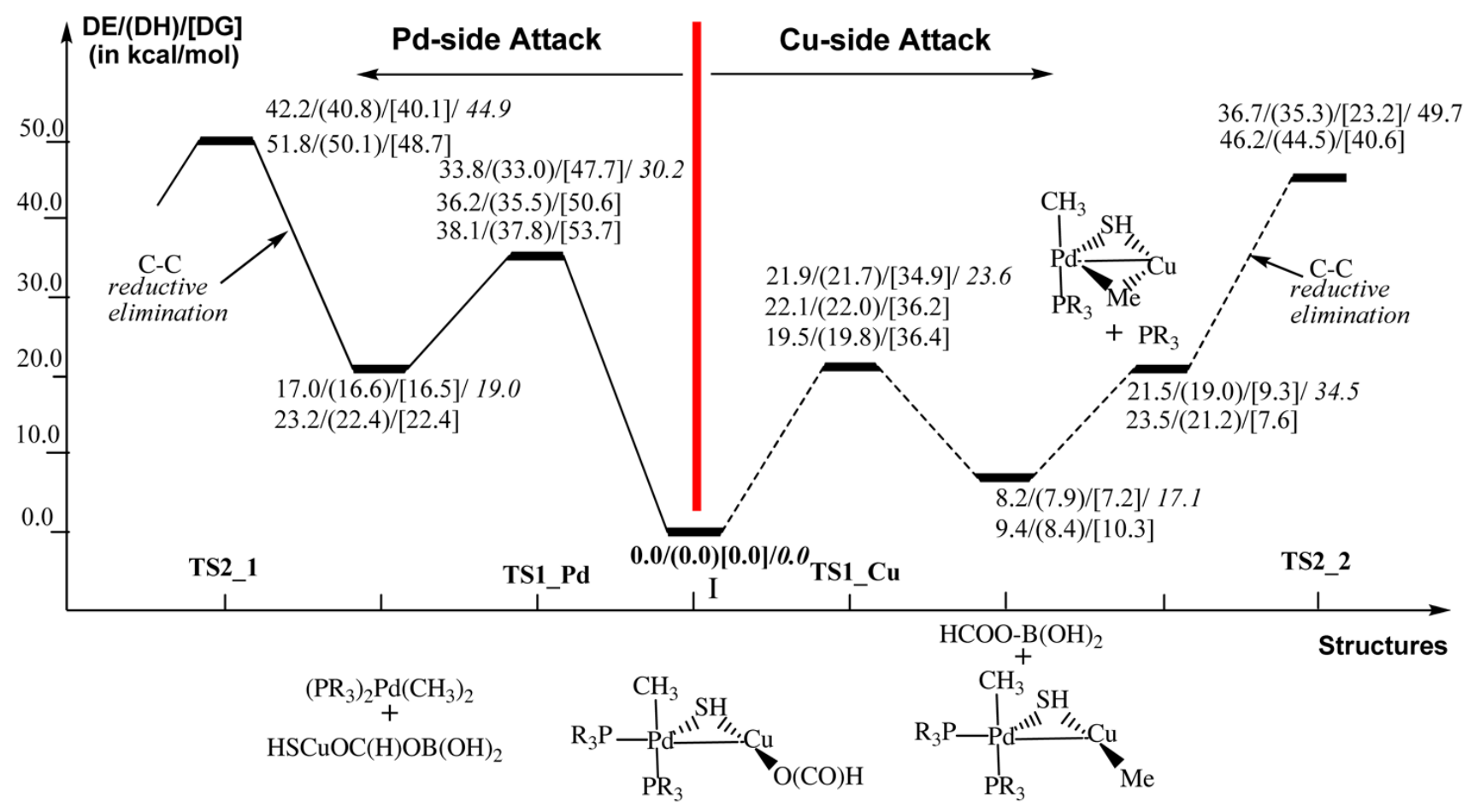

Scheme 2.

Potential Energy Surface of the Reactions (2) and (3) for 4-Coordinated Complex I.a ${ }^{\text {a }}$ Presented energies are relative to the reactants $\mathbf{I}+\mathrm{MeB}(\mathrm{OH})_{2}$ and are given in the following order, $\Delta \mathrm{E} /(\Delta \mathrm{H}) /[\Delta \mathrm{G}] / \mathrm{PCM}$. Numbers in the first, second and third lines are for $\mathrm{R}=\mathrm{H}$, Me and $\mathrm{Ph}$, respectively. 


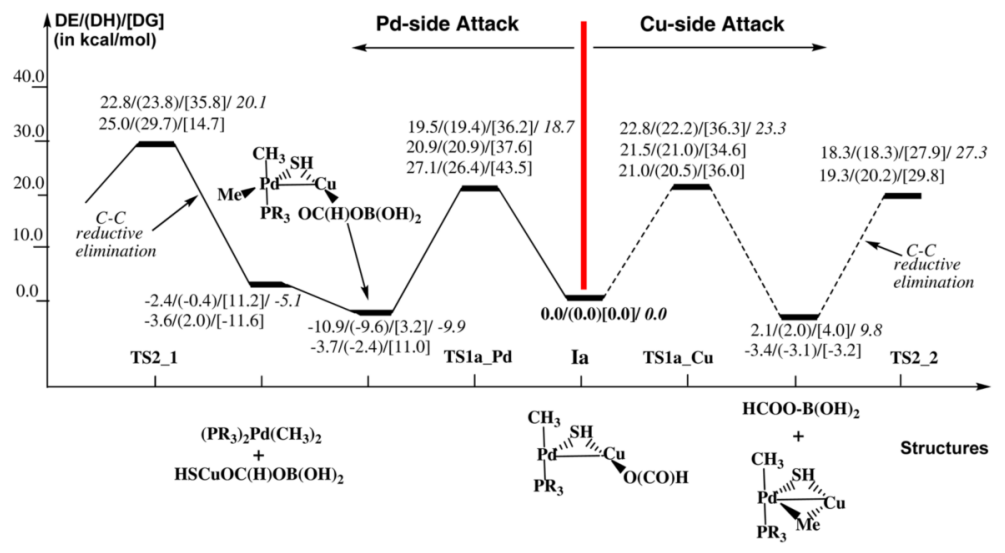

Scheme 3.

Potential Energy Surface of the Reactions (2) and (3) for 3-Coordinated Complex Ia.a aPresented energies are relative to the reactants $\mathbf{I a}+\mathrm{MeB}(\mathrm{OH})_{2}$ and are given in the following order, $\Delta \mathrm{E} /(\Delta \mathrm{H}) /[\Delta \mathrm{G}] / \mathrm{PCM}$. Numbers in the first, second and third lines are for $\mathrm{R}=\mathrm{H}$, Me and $\mathrm{Ph}$, respectively 